
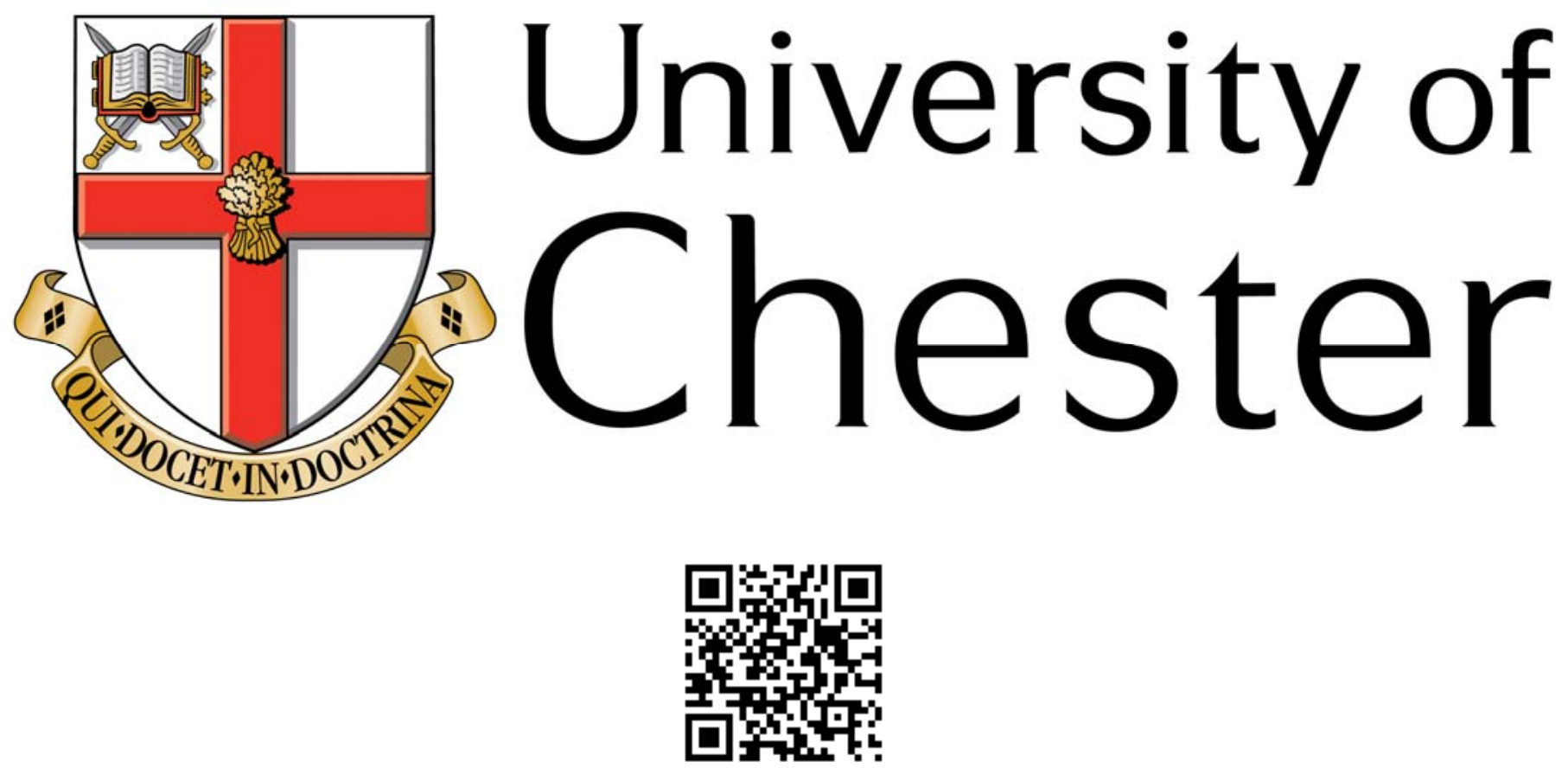

This work has been submitted to ChesterRep - the University of Chester's online research repository

\title{
http://chesterrep.openrepository.com
}

Author(s): Vera Slavtcheva-Petkova ; Victoria Jane Nash ; Monica Bulger

Title: Evidence on the extent of harms experienced by children as a result of online risks: Implications for policy and research

Date: 2014. Appeared online 8 July 2014

Originally published in: Information, Communication \& Society

Example citation: Slavtcheva-Petkova, V., Nash, V. J., \& Bulger, M. (2014).

Evidence on the extent of harms experienced by children as a result of online risks: Implications for policy and research. Information, Communication \& Society, 18(1), 48-62. http://dx.doi.org/10.1080/1369118X.2014.934387

Version of item: Authors' final draft, post-refereeing 


\title{
Original citation:
}

Slavtcheva-Petkova, V., Nash, V., \& Bulger, Monica. (2015). Evidence on the extent of harms experienced by children as a result of online risks: implications for policy and research. Information, Communication \& Society, 18(1), 48-62.

DOI:10.1080/1369118X.2014.934387

\section{Evidence on the Extent of Harms Experienced by Children as a Result of Online Risks: Implications for Policy and Research}

\author{
Vera Slavtcheva-Petkova ${ }^{\mathrm{a}}$, Victoria Jane Nash ${ }^{\mathrm{b} *}$ and Monica Bulger ${ }^{\mathrm{b}}$ \\ aDepartment of Media, University of Chester, Kingsway Buildings, Chester CH1 4BJ, UK; \\ bUniversity of Oxford, Oxford Internet Institute, 1, St Giles, Oxford OX1 3JS, UK
}

Intense media and policy focus on issues of online child protection have prompted a resurgence of moral panics about children and adolescents' Internet use, with frequent confounding of different types of risk and harm and little reference to empirical evidence of actual harm. Meanwhile, within the academic literature, the quantity and quality of studies detailing the risks and opportunities of online activity for children and young people has risen substantially in the past ten years, but this is also largely focused on risk rather than evidence of harm. Whilst this is understandable given the methodological and ethical challenges of studying Internet-related harms to minors, the very concept of risk is dependent on some prior understanding of harm, meaning that without efforts to study what harms are connected with children's online experiences, discussions of risk lack a strong foundation. This article makes a key contribution to the field by reviewing available evidence about the scale and scope of online harms from across a range of disciplines and identifying key obstacles in this research area as well as the major policy implications. The findings are based on a review of 148 empirical studies. Results were found in relation to main types of harms: health-related harms as a result of using proeating disorder, self-harm or pro-suicide websites; sex-related harms such as Internet-initiated sexual abuse of minors; and cyber-bullying.

Keywords: children; adolescents; Internet; harms; risks; policy 
The quantity and quality of academic literature detailing the risks and opportunities of online activity for children and young people has risen substantially in the past decade, in large part due to the extensive international studies funded by the European Commission as part of the EU Kids Online project. Whilst this expanding body of literature has done much to increase our understanding of what children of different ages do online, and also what strategies are employed by parents and educators to minimize risks to their wellbeing, there is still relatively little empirical evidence on the links between perceived risks and actual harms. However, distinguishing between risks and harm is vital, because risks can only be identified if we first understand what types of harms we wish to avoid. In practice, however, it is conceptually, methodologically and ethically challenging to measure harm, and as Sonia Livingstone (2010) notes, most studies in this area measure not harm, or even risk, but the "risk of risk" - "the nature and likelihood of particular risky experiences that bear an unclear relation to harm” (p. 12). Despite these difficulties, there is a body of literature, most often beyond the social sciences, that aims to measure and understand the relationship between various types of physical, emotional or psychological harm and activities online. This article reviews these studies with a view to establishing a knowledge base for further research and policy.

Conceptually, there is a long-running divide in claims regarding the alleged negative effects of mass media, although this is often over-stated. Buckingham (2007) differentiates between "two competing perspectives" (p. 4). On the one hand, researchers studying psychological effects look at the relationship between young people and the media as one of “cause and effect” (Buckingham, 2007, p. 4). On the other hand, Cultural Studies scholars investigate "the role of the media in relation to a broader range of factors" (Buckingham, 2007, p. 4). The former tend to rely on quantitative methods, especially experiments and surveys, whereas the latter often prefer qualitative methods such as interviews and discourse 
analysis, with implications for the types of conclusions that can be drawn. Small-scale qualitative studies may provide deeper insights into individuals’ experiences and their framing of the effects, but are of course not generalizable. On the other hand, large-scale quantitative studies can offer valuable insights into patterns of use and experience across representative samples of children but are unsuitable for capturing detailed evidence of harm.

Whilst this debate about the strength of media effects (and the limitations of social research generally) is undeniably healthy, the very concept of risk is dependent on some prior understanding of harm, meaning that without efforts to study what types of harms are connected with children's online experiences, all discussion of risk is surely moot. However, media scholars are not the only ones investigating the impact of the Internet and other disciplines are less hesitant about studying effects or harms. To that end, we set out to conduct a review of scholarly research across multiple disciplines addressing three research questions:

- Is there any empirical evidence detailing harms experienced by children and adolescents purportedly as a result of Internet use ${ }^{1}$ ?

- If so, what is the scope of that harm (what type of harms?)

- What is the scale of that harm (how severe, and how common)?

Our study thus helps to inform both research and policy-making, bridging the gap between different academic disciplines in identifying and analyzing available evidence about online harms experienced by children and also by providing useful summaries of recent research.

\footnotetext{
${ }^{1}$ Given that our intent is simply to expose the rich array of research that does address questions of harm, we do not ourselves impose any assumptions about the precise nature of the relationship between Internet experiences and reported harms.
} 


\section{Methods}

We undertook a literature review of peer-reviewed empirical studies of risks and harms associated with Internet use by under-18s, published in English between 1997 and 2012. We included any study reporting qualitative or quantitative data on youth Internet use. The initial literature search was conducted using online databases held by the University of Oxford libraries through the Primo Central search engine. We then conducted a second search of electronic databases such as Article First (OCLC), Web of Science, Zetoc, Science Direct and Scopus using the meta-search engine Metalib. In each case the following key-words were used: 'harm AND Internet AND children,' 'harm AND Internet AND adolescents,' 'harm AND Internet AND minors,' 'harm AND Internet AND teens' and 'harm AND Internet AND teenagers.' In addition, we followed relevant citations in journal articles and book reviews, interviewed key experts for citations, and reviewed minutes of key policy meetings for references to relevant publications. All relevant articles identified in this way were subsequently coded and analysed using the standard procedures.

\section{Criteria for inclusion and exclusion of studies}

We established broad categories for inclusion: (a) empirical work, (b) published in peerreviewed journal, (c) main focus of study was young people (aged under 18), (d) central focus on Internet use, (e) addressed incidents of harm originating from online interactions. The first two criteria thus excluded review papers, commentaries, editorials, letters, books, book chapters, and position papers. Our initial search yielded over 4,000 publications. In our first-pass review, we removed duplicate entries and reviewed titles and abstracts to determine whether the articles reported empirical work relevant to our review, excluding articles that addressed Internet use or young people, but not both. This process narrowed our corpus to 271 empirical studies. This significant reduction was due in large part to the number of duplicate articles returned, and the frequency with which the word Internet appears in journal 
abstracts for reasons other than as a focus of study.

\section{Analysis of data sources}

The remaining 271 journal articles were read in full, and as a result, 148 were found to meet our research criteria, a)-e) above. At this point, the main reasons for non-inclusion were a failure to provide empirical evidence for harm in the body of the article, or manifesting a tangential concern with children's Internet use. To ensure consistency with previous work, these 148 articles were coded by three researchers using a framework adapted from the EU Kids Online (2009) public repository. The 21-item framework included details of method, target population, context of data collection, and whether and how harm was defined or operationalized. The majority of the articles were coded by one member of the research team and then a proportion was re-coded by the other two team members to ensure inter-coder reliability. Overall, there was a high level of agreement in coding between all three members. All articles were also thematically coded, using the constant comparison method (Dye et al., 2000; Glaser, 1965). This coding process generated three topic-based clusters of articles, relating to health and self-harm (pro-eating disorder, self-harm, or suicide websites), sexual abuse or sexual content, and cyber-bullying.

\section{Results}

\section{Health-related Harms}

\section{Evidence of harm}

Our review found 63 articles providing evidence of health-related harms to minors resulting from or exacerbated by Internet use across a relatively wide range of topics. 


\section{Scope of Health-related Harms}

A majority of studies in this category (30\%) focus on eating disorders, $16 \%$ address selfharm/self-injury and 14.3\% discuss suicidal behaviours. A smaller proportion (11.1\%) discuss Internet addiction/Problematic Internet Use and 6.4\% associate Internet use with mental health issues such as depression or psychological distress. Other topics include psychological studies of aggression, sexually risky behaviours and use of stimulants and alcohol, as well as the connection between obesity and Internet use.

In asking what types of harm these studies identify, notably, 'harm' is defined in less than half (44.5\%) of the studies, and in some cases, articles referring mainly to 'perceived harm' could be more accurately interpreted as focusing on risk. The most common definition is 'self-harm' (33.3\% of all studies and $75 \%$ of those that operationalize the term). While definitions are not explicit, most seem to correspond with the definitions provided by Adams, Rodham and Gavin (2005) and Murray, MacDonald and Fox (2008). The former define selfharm as ‘parasuicide,' ‘self-mutilation,' or 'self-injury’ (p. 1293). Murray et al. (2008) explain that self-harm is "a form of actively managed self-destructive behavior that is not intended to be lethal” (p. 29). Franzen and Gotten identify a further dimension of harm, noting that message boards can normalize self-injurious behavior and can therefore be "potentially life threatening, and at worst contribute to a self-injury epidemic" (2011, p. 281), suggesting that creating or furthering certain sorts of social norms is in itself a form of societal harm beyond the physical harms any one person inflicts on themselves.

In papers related to anorexia and bulimia, the concept of harm was rarely explicitly operationalized but is implicitly treated as the development or sustenance of these disorders. Other harmful outcomes are considered, for example normalization of anorexia as a lifestyle (Csipke \& Horne, 2007). ‘Problematic Internet Use’ or Internet addiction is a controversial concept, and studies considering this phenomenon endeavor to unpack the possible harms 
entailed by cataloguing the negative effects associated with excessive Internet use, for example, “isolation, feelings of emptiness, debt, marital conflict and/or breakdown, family problems, significant weight gain, or neglecting basic needs such as washing, eating, or sleeping” (Acier \& Kern, 2011). Other examples of health-related harm found in our review include "desensitization to violence in real life and impairment in the process and outcome of moral evaluation,” (Funka, Buchman, Jenksa, \& Buchtoldta, 2003, p. 414) and physical or emotional harm.

\section{Scale of health-related harms}

It's difficult to draw unequivocal conclusions regarding the severity and frequency of healthrelated harms. First, these studies draw limited conclusions about the incidence of harms across the general population of minors, more frequently focusing on individuals with prior problems. Second, some studies (not unreasonably) assume that certain phenomena are incidents of harm in their own right, without unpacking their actual impact on young Internet users. For example, researchers analyzing the content of pro-eating disorder websites highlight potentially worrisome features, such as the $85 \%$ of websites in Borzekowski, Schenk, Wilson and Peebles’s (2010) study that contain “thinspiration” material (p. 1526). Another difficulty concerns balancing negative and positive effects. Thus for example, studies of pro-eating disorder websites note that these websites purport to support followers but often contain harmful content such as "reinforcement of disordered eating, and prevention of help-seeking and recovery” (Rouleau \& von Ranson, 2011, p. 525).

The most valuable studies proffer evidence of how this information is applied by users, and the consequent scale of harms: in one US survey, as many as $96 \%$ of users of proeating disorder websites and $46.4 \%$ of users of pro-recovery sites report "learning new weight loss or purging techniques” (Wilson, Peebles, Hardy, \&Litt, 2006, p. e1635). Csipke 
and Horne’s study (2007) provides further insight with 19.2\% of users saying they feel that pro-eating disorder websites are harmful to them because they encourage the disorders and even competition among participants or because they have a "negative impact on self-affect" (p. 200). Again, however, two distinct groups are outlined: $17 \%$ who felt the websites helped them restrict their eating and maintain "other abnormal behaviour" and $43 \%$ who felt they had benefitted from the "emotional” support because they were able to "share their experiences” (p. 200).

Although this area of research is well-populated by high quality studies across a wide range of journals in medicine and psychology, there's a recognized need for further research. For example, Talbot (2010) notes two important caveats. First, that “viewing pro-ED websites may increase eating disorder behavior but might not cause it” (p. 686), and second, that "more research is needed in order to determine if these websites do harm, and if so, to whom and of what form” (p. 694). Further, opinion seems sharply divided as to whether even allegedly pro-support oriented websites normalize and encourage pro-eating disorders. Thus in their review of the field, Sharpe and her colleagues (2011) differentiate between pro-eating disorder content websites and websites that provide "support and a sense of community" (p. 34). They claim that the latter "may be perceived beneficial" and that "there is no clear indication that such sites promote the development or maintenance of eating disorders” (p. 34), a conclusion with important implications for those who wish to ban all such websites.

The limited evidence available with regard to pro-suicide websites seems much more conclusive in the claims made about the associated harms. One meta-study concludes that "Pro-suicide websites and online suicide pacts were observed as high-risk factors for facilitating suicidal behaviours, particularly among isolated and susceptible individuals” (Durkee, Hadlaczky, Westerlund, \& Carli, 2011, p. 3938). However, once again, the authors are wary of condemning all suicide forums noting that some research has identified "an 
opportunity to meet other people who share similar experiences, wherein their thoughts and feelings are not condemned nor lectured about” (p. 3944). A similar discussion was evident in the self-harm literature.

As above, these studies distinguish between the role of websites and fora in distributing information that might facilitate suicide, in inciting it and in establishing pacts between suicidal individuals, all of which are portrayed as harmful (Becker, Mayer, Nagenborg, El-Faddagh, \& Schmidt., 2004; Biddle, 2008; Naito, 2007). There are also suggestions that the Internet may exacerbate existing risks, illustrated by examples of individuals who commit to killing themselves in online suicide fora and then feel they can’t back down (Baume, Cantor, \&Rolfe, 1997).

Finally, the last major category of health-related harm captured in the review concern the link between Internet use and psychological concerns such as Problematic Internet Use (PIU) and Internet addiction. An investigation of reports by mental health professionals in the USA (Mitchell, Becker-Blease, \& Finkelhor, 2005) shows that 35\% of people with problematic Internet experience, mainly overuse, are under the age of 18. However, they make an important point that "virtually all of the Internet problem behaviors" are "extensions of problem behaviors that pre-existed the advent of the Internet” (p. 506). Acier and Kern (2011) also solicit the views of addiction counsellors in Canada. They explain that the typical problematic Internet user is a teenager spending large amounts of time online, including at night. He or she is "significantly socially isolated” and plays online games on average between 12 and 14 hours a day, in some cases spending "up to 36 hours without sleeping or washing” (Acier and Kern, 2011, p. 985). Various negative effects are reported: “isolation, feelings of emptiness, debt, marital conflict and/or breakdown, family problems, significant weight gain, or neglecting basic needs such as washing, eating, or sleeping” (Acier \& Kern, 2011, p. 986). PIU also seems to be linked to self- harm: in one Chinese 
study, users who are "moderately” or "severely addicted” to the Internet were 2.4 times more likely to have committed self-injurious behavior between one and five times in the past six months (Lam et al., 2009, p. 403).

Overall, studies on health-related harm depict an array of significant harms, some of which affect large proportions of users of specific types of sites, albeit users who are often already vulnerable. In this context, harm is most commonly discussed in terms of self-harm, harm related to the use of websites promoting eating disorders or suicide, and Problematic Internet Use. Less than half the studies define harm and many (especially those addressing pro-eating disorders websites) discuss the potential for harm by conducting textual analysis of the websites. In some areas, however - most notably, pro-suicide websites - evidence suggests that significant harm does indeed occur but explanations of how the process unfolded are rare.

\section{Sex-related harms}

\section{Evidence of sex-related harm}

Our review identified 49 articles detailing evidence of sex-related harms resulting from minors' online experiences, dominated, as might be expected, by studies of online solicitation and child abuse, however this category also includes articles addressing the effects of minors' own sex-related experiences online, such as viewing pornography or engaging in risky sexual behavior.

Scope of sex-related harms.

The 49 studies in this category fall into three broader, overlapping topical groups: process, 
predictors, outcomes (see table 1$)^{2}$. The majority of studies address either processes or predictors of sexual offense. Studies of process typically analyze, from the perspective of offenders or victims, how Internet-initiated sexual abuse occurs. Studies of predictors of sexual offense include offenders' characteristics, risks and risk factors, and the association between the consumption of child pornography ${ }^{3}$ and offline child sexual abuse. While fewer studies (25\%) examine outcomes, this research considers the effects of being exposed to pornography or sexually explicit material or being a victim of Internet-related sexual abuse.

Harm is operationalized in just $33 \%$ of the studies. $44 \%$ of those who operationalize the term (14\% of all sex-related studies) define it as emotional/psychological harm. Thus, although victims of child pornography report different degrees of severity of harms resulting from their abuse, Prichard, Watters and Spiranovic (2011) find “considerable trauma arising from the knowledge that records of their abuse circulate on the Internet”, and as a whole the “psychological and physical harms can be terrible” (p. 587).

In $37.5 \%$ of the studies in which harm is defined, it is operationalized as sexual abuse, including rape. When the definition of harm revolves around sexual abuse, a number of researchers (Prichard et al., 2011; Quayle \& Taylor, 2002; Sheehan \& Sullivan, 2010; Winder \& Gough, 2010) report a tension in offenders' accounts of what constitutes harm. Users of child pornography seem to differentiate between sexual contact, which they define as harmful and viewing of child pornography, which is either not perceived as a harm or just "minimal harm” (Prichard et al., 2011, p. 587). In addition to operationalizing harm as physical or

\footnotetext{
${ }^{2}$ The percentages in table 1 do not add to $100 \%$ precisely because of overlaps between the categories. Three articles discuss all three key topics, five articles discuss both risks and outcomes, four focus on processes and risks and three on processes and outcomes.

${ }^{3}$ Although the term 'child pornography' may be more accurately replaced with the term 'child abuse images' we employ it when used by the articles reviewed.
} 
psychological traumas enacted on a third party, some of these studies also consider the potential negative first-person effects of consuming sexual content online such as desensitization to abusive images and behaviors (Lo, Wei, \& Wu, 2010). Other definitions include social harm and self-harm.

\section{Scale of sex-related harms}

Studies of sexual abuse included in this review tend to focus on the predictors, prevalence, processes or impacts upon the victim. In terms of risk factors and predictors of child sexual abuse, a key (and highly-charged) topic concerns whether downloading child abuse images online is related to sexually abusing children offline. Researchers do not provide a definitive answer. Thus, in a Dutch study of 38 first-offense Internet downloaders of indecent child images, the authors (Buschman, Wilcox, Krapohl, Oelrich, \& Hackett., 2010) claim that the downloading of child pornographic images may be a predictor of offline sexual harming of children. "An interest in child abuse images is strongly correlated to an interest in active sexual abuse and that such sexual harming of children is a strong sexually motivating stimulus for contact sex offenders” (p. 208). A Swedish review (Endrass et al., 2009) of the court convictions of 231 men reveals an opposite trend - the authors find "consuming child pornography alone is not a risk factor for committing hands-on sex offenses (n.a.)” A US study (McCarthy, 2010) of 110 male child pornography offenders shows that contact offenders are more likely than non-contact offenders to be involved with minors online and to communicate with others with similar interests. Another US study (Briggs et al., 2011) based on convicted offenders' files from a forensic mental health center, suggests there are actually two very different subgroups: “a contact-driven group motivated to engage in offline sexual behavior with an adolescent and a fantasy-driven group motivated to engage an adolescent in online cybersex without an express intent to meet offline” (p. 72). 
Looking at the prevalence of Internet-related child sexual abuse, it's obvious that the scale of harm is extensive. Mitchell, Jones, Finkelhor and Wolak (2011) report that in 2006 there were 569 arrests for Internet-facilitated commercial sexual exploitation of children in the USA. $64 \%$ of the arrested had used the Internet to purchase or sell child pornography images whilst a further $36 \%$ had used the Internet to purchase or sell access to children for sexual purposes. A Swedish review of 315 police reports (Shannon, 2008) demonstrates the variety of ways in which online activities can facilitate abuse; in 179 cases the perpetrator's contact with the victim was entirely online with abuse involving sexual conversations and exposure via webcam, in 22 cases an adult used the Internet to develop a sexual relationship with a known acquaintance and in 69 cases contact was initially established online but led to offline sexual abuse. Arrests are clearly a very poor measure of the prevalence of onlinerelated sexual abuse of minors, but the studies reported here give some indication of the range of harms enacted, if not the absolute scale.

Another research approach considers the prevalence of sexual solicitation online, although these studies cannot usually identify whether an adult or minor was behind the solicitation, nor do they give a clear picture of the outcomes of these encounters, which may or may not be harmful in their own right. In a Dutch representative sample (Baumgartner, Valkenburg, \& Peter, 2010) as many as $5.6 \%$ of boys and $19.1 \%$ of girls aged 12 to 17 report having been sexually solicited on the Internet at least once in the past six months. In a US national cross-sectional study (Ybarra \& Mitchell, 2007), 15\% of the 10 to 15 year olds report an unwanted sexual solicitation online in the last year, however in both cases it is difficult to draw conclusions about harms without knowing more about recipient reactions.

Several studies illuminate how online spaces are used to facilitate sexual encounters and abuse; the Ybarra and Mitchell study (2007) reports that of the 15\% of 10-15 year olds solicited online, a quarter experienced this in a social networking site whilst Malesky (2007) 
shows that 25 of his 31 participants report having used chat rooms in an attempt to get in touch with children and adolescents. A third presented themselves as minors and almost all engaged in sexually explicit conversations with the young people. However, at least one study of paedophiles' forums shows that most users advise against starting online relationships with children because of the "high likelihood of detection" (Holt, Blevins, \& Burkert, 2010, p. 17).

In terms of the scale of harms described, the most upsetting material relates to the various physical and psychological negative effects experienced by child victims of abuse. A German study (Von Weiler, Haardt-Becker, \& Schulte, 2010) of 245 confirmed and 280 suspected victims of child pornographic exploitation shows that victims suffer from feelings of shame, hate and disgust. Girls also suffer from fear and repression while boys experience guilt and speechlessness. Those treating victims also noted that the victims "felt publicly humiliated, horrified and distressed” (p. 218) by the persisting online availability of the images, a finding corroborated by other studies (e.g., Leonard, 2010), supporting policy concerns about the Internet’s constant “re-victimization” of abuse victims. Leonard (2010) concludes Internet offending cannot be viewed as "causing fewer traumas than contact offending” (p. 255).

Whilst the majority of this literature focuses on the effects of online-initiated sexual abuse, there is also evidence of minors commonly viewing general pornographic material both wanted and unwanted exposure, but with less evidence of harms that result from this. Wolak, Mitchell, and Finkelhor's representative sample survey (2007) show that $42 \%$ of American 10 to 12 year olds have viewed online pornography in the past year - $66 \%$ of which was unwanted exposure, whilst a large-scale cluster-sampled Taiwan study (Lo \& Wei, 2005), found that $38 \%$ of the 13 to 17 -year olds report having surfed pornographic websites. It should be pointed out, however, that for some youth accessing pornographic 
material might be the main means of finding information about sexuality, so again surveys as such tell us little about the actual "effects” and "harm” of viewing pornographic material.

Overall, the studies investigating sex-related harms report an extensive scale of harm in some areas such as Internet-facilitated child sexual abuse but the evidence on the link between offline and online sexual solicitation remains inconclusive. Moreover, although a quarter of the studies describe the negative effects of Internet-related sexual abuse or exposure to pornography and sexually explicit material mainly in terms of emotional/psychological harm, definitions of harm are actually rare in this body of literature since the term is only operationalized in a third of studies.

\section{Cyber-bullying}

Evidence of harms associated with cyber-bullying.

36 articles in our review discuss harms or potential harms related to cyber-bullying. Just over a third of this group (36\%) focus on cyber-bullying's prevalence, whilst a sixth investigate the impact of cyber-bullying. $11 \%$ and $8 \%$, respectively, look at the association between cyber-bullying and depression or aggression and delinquency. $11 \%$ consider the predictors of cyber-bullying.

Scope of harms associated with cyber-bullying.

In terms of identifying what types of harms are associated with cyber-bullying, only around a quarter of the articles explicitly operationalize the concept of harm. The remainder either define cyber-bullying as involving harm or assume that cyber-bullying equals harm. A clear picture of the negative impacts associated with the different contexts or manifestations of cyber-bullying is therefore difficult to form. 
Patchin and Hinduja (2006) provide the most commonly referenced definition, that cyber-bullying is the "willful and repeated harm inflicted through the medium of electronic text" (p. 152) later updated to "the intentional and repeated harm of others through the use of computers, cell phones, and other electronic devices” (Hinduja \& Patchin, 2008, p. 5). In their work Hinduja and Patchin (2007) provide a notable exception to most of their colleagues in the field by also clearly defining harm. They argue that although cyber-bullying might not be considered harmful, because "it generally does not involve direct physical contact between the offender and the victim...victims of cyber-bullying may be at risk for other negative developmental and behavioral consequences - including school violence and delinquency” (Hinduja \& Patchin, 2007, p. 103). In their early work, Patchin and Hinduja (2006) claim that "the negative effects inherent in cyber-bullying, though, are not slight or trivial and have the potential to inflict serious psychological, emotional, or social harm. When experienced among members of this highly impressionable and often volatile adolescent population, this harm can result in violence, injury, and even death” (p. 149).

These two types of harms - psychological and physical - are most often included in definitions of cyber-bullying and for most researchers, psychological harms seem more significant than physical ones. The issue of physical harm is brought up mainly when comparing cyber-bullying to traditional bullying. As Huang and Chou (2010) argue, the dominant view is that "cyber-bullying hurts teenagers emotionally, rather than result directly in physical damage” (p. 1581). This focus on the psychological and emotional effects lead some researchers to conclude that "the physical scars of a beating can heal, and it is often possible for the would-be victim of such a beating to run away; stalked by someone online, even the strongest mind can break and there is no place to hide” (Huang \& Chou, 2010, p. 1581). Baker and Tanrikulu (2010) catalog a list of “negative psychological outcomes” of cyber-bullying such as "frustration and sadness", “depression, confusion, guilt, shame, self- 
harm, distress and withdrawal from friends” (p. 2772). Smith et al.’s (2008) study provides additional nuance, with pupils explaining how they interpret the "harmfulness" of bullying across different media (p. 381).

Scale of harms associated with cyber-bullying.

It's difficult to get a clear picture of the prevalence of online bullying and resultant harms simply because the reported prevalence of cyber-bullying varies substantially - from 9\% (Ybarra, Mitchell, Wolak, \& Finkelhor 2006) or 15.8\% (Schneider ,O'Donnell, Stueve, \&Coulter, 2012) to 72\% (Juvonen \& Gross, 2008) among fairly similar age groups. There are a number of explanations for such variation. First, not all studies are representative, some rely on online samples (in which age cannot be verified) and sample sizes vary considerably - from around 100 to more than 20,000 participants. Second, time periods and national contexts differ. A Spanish study (Calvete, Orue, Estévez, Villardón, \& Padilla, 2010), reports that $44.1 \%$ have experienced cyber-bullying, while the US national representative Second Youth Internet Survey (SYIS) found that 9\% of young people had experienced some form of Internet harassment (Ybarra et al., 2006). Third, cyber-bullying is operationalized in different ways. Some studies (e.g., Kowalski \& Limber, 2007) draw on the Olweus Bully/Victim Questionnaire, while others devise their own measures. The studies also report differences in prevalence across different demographics: Smith’s (2008) Swedish sample, for example, shows significant variations between lower secondary pupils (17.6\%) and sixthformers (3.3\%), a finding backed up by Williams and Guerra (2007). Gender is also a relevant factor, with girls more likely to face cyber-bullying than boys (Kowalski \& Limber, 2007).

Studies that measure the association between cyber-bullying/Internet harassment and psychological “consequences” (Baker \& Tanrikulu, 2010, p. 2771) such as distress and 
depression provide conclusive evidence that such an association exists. Schneider et al. (2012) found that "bullying victimization was consistently and robustly associated with an increased likelihood of psychological distress across all measures from depressive symptoms and suicidal ideation to reports of self-injury and suicide attempts” (pp. 173-174), a finding corroborated by Ybarra (2004). Schneider et al.’s (2012) study also reported evidence of "lower school performance and school attachment” (p. 171). The authors looked at both traditional bullying and cyber-bullying, with victims of both cyber and traditional bullying most likely to experience psychological issues, followed by those victimized solely online.

Similar to other abuses reported here, the prevalence of cyberbullying is difficult to estimate, because significant disparities exist in current research and reporting. It is additionally difficult to estimate the extent of harms, since harm is operationalized in less than a quarter of the articles and is most often associated with psychological harm rather than physical harm.

\section{Discussion}

The aim of this review was to collate, appraise and synthesize evidence pertaining to harms resulting from children's use of the Internet. In doing so, the wider objective was to expand the focus of researchers and policy-makers from considering just the risk of risk to broader questions of why those risks might matter. Whilst we don’t need to read clinical research studies to know that child sexual abuse or suicide attempts are harmful, such studies are invaluable in helping us to understand which risks are most significant, for whom and why. They also remind us that as researchers, it's vital that we approach such studies reflexively, to avoid imposing our own definitions of harm on our research subjects, especially where these may be tinged with unacknowledged moral, cultural or political bias. 
As already indicated, the study has clear limitations. First, the framing of the review will of course have shaped our results. The focus on harm as a search term means that some potentially relevant studies that fail to use the word harm may have been omitted. Similarly, the focus on harm as a concept means that studies focusing solely on risks were discarded from our analysis. Second, we artificially narrowed our search by reviewing only peerreviewed journal articles as these contain the most up-to-date research and tend to have passed through the most stringent quality control processes (as most book chapters and book reviews do not undergo blind peer review). In addition, we reviewed only studies published in English, meaning that potentially relevant studies in other languages were discarded, although these may have shed light on the extent to which the operationalization of harm is contingent on the relevant cultural, political and national contexts. Third, the decision to give equal weight to both qualitative and quantitative studies rules out the possibility of a quantitative meta-analysis. Finally, although we included all studies that used the word harm, regardless of whether harm was actually operationalized or not, there is clearly a level of subjectivity involved in deciding whether a researcher has operationalized the term or not.

Despite these limitations, our review of the evidence indisputably demonstrates that there is a rich stream of academic research which can and should inform our understanding of the harms, rather than just the risks that are associated with children's Internet use. Vitally, such studies can deepen our understanding of the complex and often multi-faceted nature of those incidents of harm, and provides a better understanding of how to support or treat those affected, as well as which risks factors are most important. It also helps to provide some indication of the prevalence and seriousness of those harms, which is vital for the design of effective and measured policy interventions. We strongly recommend that deeper and broader reviews of this literature are carried out, extending far beyond the limits of our study; the aim 
here is simply to demonstrate the benefits and importance of considering harm as well as risk.

We note that the evidence in some areas is more conclusive than in others.

Documented examples of actual harms include children being sexually abused and psychologically or physically traumatized as a result of establishing initial online contact with a perpetrator, young people assisted or encouraged in their suicide attempts after visiting pro-suicide forums and adolescents feeling encouraged to pursue their eating disorders or self-injurious behavior as a result of regularly using pro-eating disorder or self-harm websites. The most telling and disturbing cases are based on the examples documented in police, hospital, court and medical records.

In numeric terms, the figures are often low - the number of children experiencing such extreme harm is small in comparison with the overall number of Internet users. While in theory every child has an equal probability of experiencing such harm, the available evidence reminds us that some children are always more at risk than others, usually those vulnerable on other measures. There is remarkably little evidence to suggest significant harms often affect children without prior evidence of problems or risky behavior. For example, in the area of self-harm and pro-eating disorder websites, there is hardly any evidence that indicates whether young people previously unaffected by self-harm or eating disorders are influenced by these websites. Moreover, scholars also disagree as to whether sufferers of anorexia or bulimia find the community support aspects of these websites helpful or harmful, whilst, on the societal and political level we should also consider whether even furthering certain forms of social norm (of body image, or eating habits) can itself be seen as a form of societal harm. Although the same questions arise in relation to pro-suicide websites, here the severity of the harm seem indisputable, and both researchers and policy makers should turn their attention to this type of harm. 
While it is undeniable that some studies present strong evidence for the harms experienced by children as a result of online risks, it is only fair to conclude that the majority of studies reviewed in this article do not provide conclusive evidence. A number of key obstacles stand in the way of researchers. First, many scholars do not operationalize harm in their reporting. They use the term without defining it and this hinders them from making firm conclusions about the proliferation, nature and extent of harm. Cyber-bullying studies are a good example here. Undeniably, cyber-bullying affects a significant number of young people, indeed it seems to be the most commonly-experienced source of Internet-related harm. However, because so many studies assume that cyber-bullying is intrinsically harmful without unpacking the nature of the harm inflicted, there is not enough evidence (and consequent understanding) of longer term mental health effects, educational outcomes, or differing levels of resilience in those affected etc. Further, the majority of studies in the field are based on surveys and self-reported measures with no studies found to use ethnographic methods, which would considerably enrich our understanding of cyber-bullying harm.

This leads to the second main limitation of the studies, namely the reliance on the survey as a method of data collection. While surveys, especially representative ones, give good indications about the scale and prevalence of certain issues such as cyber-bullying, online solicitations or access to online pornography, as a research instrument surveys may not be the most effective method of measuring harm. Children's charities argue that children who are victims of serious harms may never disclose the abuse (Farmer, 2010). Thus, surveys can tell us a lot about the risks experienced by children or the prevalence of certain issues such as cyberbullying but rather less about actual harms experienced by online users. For some topics, methods such as participant observation seem more informative as a number of the articles on eating disorders or self-harm demonstrate. Textual analyses of websites also represent a rich and interesting source of information about young people’s online 
experiences but unless linked with users’ perceptions, they cannot provide conclusive evidence about harms because they rely on researchers' subjective evaluations of potential harms. An increased combining of quantitative and qualitative methods would certainly provide a deeper understanding of harms in terms of both their scale and scope.

A third limitation of the studies reviewed concerns the imbalance between different research areas. The studies in the sexual abuse field are an excellent example of how a broad research base can make an important contribution to our understanding of online risks and harms. The field includes studies based on police reports, court records or clinical files as well as surveys and interviews. Researchers seek victims’ and perpetrators' views and in some cases parents are also contacted. In other areas, however, there is much more scope for research. As already indicated, there is too little evidence about the impact of pro-eating disorder, self-harm and pro-suicide websites on healthy minors. There is much to be gained by pursuing ethnographic approaches, namely observing interactions in these websites and following them up with interviews or other methods of data collection, as well as undertaking more research with those being treated for such disorders.

A final weakness concerns the apparent lack of research on some particularly salient policy issues, such as privacy-related harm or commercial exploitation. Whilst it is possible that the limited nature of the search terms used in this study meant that important research on these topics was missed, there is also reason to suspect that topics such as these are generally under-researched due to the methodological and ethical challenges of investigating such harms. There is certainly a clear need for more detailed review of research evidence in these areas.

\section{Conclusions}

The findings of this study offer two very important lessons for policy makers. First, the 
proportion of children experiencing severe harms as a result of online experiences might not be that high in numeric terms but the severity of harms inflicted is so significant that it is deserving of substantial resources and attention. But the number of those experiencing more minor harms such as those caused by online bullying are high and may therefore deserve more attention than currently received. Second, the diversity of topics discussed and types of harm identified seems to suggest that a one-size-fits-all solution will not work when it comes to online protection of minors. Banning or filtering all potentially harmful websites across different subject areas might be more damaging than useful. While some websites are clearly harmful such as child sexual abuse websites, others are more controversial because while they can lead to perpetuating harmful behavior in some cases, they may also provide useful support networks for troubled individuals in others.

A third lesson is that policy makers also need to give more consideration to the fact that some young people are more at risk than at others: young people from disadvantaged households with a history of abuse are particularly vulnerable; policy tools targeted at the less vulnerable majority may not be effective in protecting this group. It should also be remembered that the need to protect young people from online harms must always be balanced against the need to protect their rights (and opportunities) to freely express themselves and seek information online.

Finally, this study makes an important contribution to a growing body of research into young people’s online experiences by identifying and critically analyzing the available evidence for the harms experienced by minors as a result of online risks. The research reviewed here is most valuable in reminding us why certain types of risk matter, and therefore why particular interventions might be justified. The dominant focus in media and communications research on identifying the range and prevalence of risk factors affecting certain groups of young Internet users has contributed greatly to our understanding of how 
individual, social and technological factors interplay to place some youngsters at risk of harm. But a focus on risk, or the risk of risk to the exclusion of harm is ultimately selfdefeating, for without research into the types of harm experienced, we cannot know who is at risk, or why that should matter, and may fail to notice certain new or emerging sources of concern. 


\section{References}

Acier, D., \& Kern, L. (2011). Problematic Internet use: Perceptions of addiction counsellors. Computers \& Education, 56(4), 983-989.

Adams, J., Rodham, K., Gavin, J. (2005). Investigating the 'self' in deliberate self-harm, Qualitative Health Research, 15(10), 1293-1309.

Baker, Ö, \& Tanrikulu, I. (2010). Psychological consequences of cyber bullying experiences among Turkish secondary school, Procedia - Social and Behavioral Sciences, 2(2), $2771-2776$.

Baume, P., Cantor, C., \& Rolfe, A. (1997). Cybersuicide: the role of interactive suicide notes on the Internet, Crisis, 18(2), 73-79.

Baumgartner, S., Valkenburg, P., \& Peter, J. (2010). Unwanted online sexual solicitation and risky sexual online behavior across the lifespan. Journal of Applied Developmental Psychology, 31(6), 439—447.

Becker, K., Mayer, M., Nagenborg, M., El-Faddagh, M., \& Schmidt, M. (2004). Parasuicide online: Can suicide websites trigger suicidal behaviour in predisposed adolescents? Nordic Journal of Psychiatry, 58(2), 111-114.

Biddle, L. (2008). Suicide and the Internet. Journal of Medical Internet Research, 336, 800_802.

Borzekowski, D., Schenk, S., Wilson, J., \& Peebles, R. (2010). e-Ana and e-Mia: A content analysis of pro-eating disorder websites, American Journal of Public Health, 100(8), $1526-1534$.

Buckingham, D. (2007). The Impact of the Media on Children and Young People with a particular focus on computer games and the internet. Prepared for the Byron Review on Children and New Technology. Retrieved from: www.lloydminster.info/libdocs/byronreview/annex_g.pdf

Buschman, J., Wilcox, D., Krapohl, D., Oelrich, M., \& Hackett, S. (2010). Cybersex offender risk assessment. An explorative study, Journal of Sexual Aggression, 16(2), 37-41.

Briggs, P., Simon, W., \& Simonsen, S. (2011). An exploratory study of Internet-initiated sexual offenses and the chat room sex offender: has the Internet enabled a new typology of sex offender? Sexual Abuse: A Journal of Research and Treatment, 23(1), 72-91. 
Calvete, E., Orue, I., Estévez, A., Villardón, L., \& Padilla, P. (2010). Cyber-bullying in adolescents: Modalities and aggressors’ profile, Computers in Human Behavior, 26(5), 1128-1135.

Csipke, E., \& Horne, O. (2007). Pro-Eating Disorder Websites: Users’ Opinions, European Eating Disorders Review, 15, 196-206.

Durkee, T., Hadlaczky, G., Westerlund, M., \& Carli, V. (2011). Internet pathways in suicidality: a review of the evidence, International journal of environmental research and public health, 8(10), 3938-3952.

Dye, J., Schatz, I., Rosenberg, B., \& Coleman, S. (2000). Constant comparison method: a kaleidoscope of data. Qualitative Report 4(1/2). Retrieved from www.nova.edu/ssss/QR/QR4-1/dye.html.

Endrass, J., Urbaniok, F., Hammermeister, L., C Benz, C., Elbert, T., Laubacher, A., \& Rossegger, A. (2009). The consumption of Internet child pornography and violent and sex offending, BMC Psychiatry, 9.

EU Kids Online. (2009). EUKidsOnline Coding for Entering Data into the Repository Retrieved from

http://www.lse.ac.uk/media@lse/research/EUKidsOnline/EU\%20Kids\%20I\%20\%282 006-9\%29/codingframework\%20.pdf

Farmer, E. (2010) What do we know about child sexual abuse? (Unpublished report.) London: National Society for the Prevention of Cruelty to Children.

Franzén, A., \& Gottzén, L. (2011). The beauty of blood? Self-injury and ambivalence in an Internet community, Journal of Youth Studies, 14(3), 279-294.

Funka, J., Buchmanb, D., Jenksa, J., \& Bechtoldta, H. (2003). Playing violent video games, desensitization, and moral evaluation in children, Journal of Applied Developmental Psychology, 24(4), 413-436.

Glaser B (1965) The constant comparative method of qualitative analysis. Social Problems 12(4): 436-445.

Hinduja, S., \& Patchin, J. W. (2007). Offline Consequences of Online Victimization: School Violence and Delinquency, Journal of School Violence, 6(3), 89-112.

Hinduja, S., \& Patchin, J. W. (2008). Personal information of adolescents on the Internet: A quantitative content analysis of MySpace, Journal of Adolescence, 31(1), 125-146.

Holt, T. J., Blevins, K. R., \& Burkert, N. (2010). Considering the pedophile subculture online, Sexual Abuse: A Journal of Research and Treatment, 22(1), 3-24. 
Huang, Y., \& Chou, C. (2010). An analysis of multiple factors of cyber-bullying among junior high school students in Taiwan, Computers in Human Behavior, 26(6), 1581— 1590.

Juvonen, J., \& Gross, E. (2008). Extending the school grounds? Bullying experiences in cyberspace, The Journal of School Health, 78(9), 496-505.

Kowalski, R., \& Limber, S. (2007). Electronic bullying among middle school students, The Journal of Adolescent Health, 41, S22-S30.

Lam, L. T., Peng, Z., Mai, J., \& Jing, J. (2009). The association between internet addiction and self-injurious behavior among adolescents, Injury Prevention, 15(6), 403-408.

Leonard, M. (2010). 'I did what I was directed to do but he didn't touch me': The impact of being a victim of internet offending, Journal of Sexual Aggression, 16(2), 249-256.

Livingstone, S. (2010). e-Youth: (future) policy implications: reflections on online risk, harm and vulnerability, Originally presented at e-Youth: balancing between opportunities and risks, UCSIA \& MIOS University of Antwerp, Antwerp, Belgium.

Lo, V., Wei, R., \& Wu, H. (2010). Examining the first, second and third-person effects of Internet pornography on Taiwanese adolescents: implications for the restriction of pornography, Asian Journal of Communication, 20(1), 90-103.

Lo, V., \& Wei, R. (2005). Exposure to Internet pornography and Taiwanese adolescents' sexual attitudes and behavior, Journal of Broadcasting \& Electronic Media, 49(2), $221-237$.

Malesky, A. (2007). Predatory online behavior: Modus operandi of convicted sex offenders in identifying potential victims and contacting minors over the Internet, Journal of Child Sexual Abuse, 16(2), 23-32.

McCarthy, J. (2010). Internet sexual activity: A comparison between contact and non-contact child pornography offenders, Journal of Sexual Aggression, 16(2), 181-195.

Mitchell, K., Becker-Blease, K., \& Finkelhor, D. (2005). Inventory of problematic Internet experiences encountered in clinical practice, Professional Psychology: Research and Practice, 36(5), 498-509.

Mitchell, K., Jones, L., Finkelhor, D., \& Wolak, J. (2011). Internet-facilitated commercial sexual exploitation of children: findings from a nationally representative sample of law enforcement agencies in the United States, Sexual Abuse: A Journal of Research and Treatment, 23(1), 43-71.

Murray, C., Macdonald, A., \& Fox, J. (2008). An Internet survey of adolescent self-injurers, Australian e-Journal for the Advancement of Mental Health, 4(1). 
Naito, A. (2007). Internet suicide in Japan: Implications for child and adolescent mental health, Clinical Child Psychology and Psychiatry, 12(4), 583-597.

Patchin, J. W., \& Hinduja, S. (2006). Bullies move beyond the schoolyard: A preliminary look at cyber-bullying, Youth Violence and Juvenile Justice, 4(2), 148-169.

Prichard, J., Watters, P., \& Spiranovic, C. (2011). Internet subcultures and pathways to the use of child pornography, Computer Law \& Security Review, 27(6), 585-600.

Quayle, E., \& Taylor, M. (2002). Child pornography and the Internet: Perpetuating a cycle of abuse, Deviant Behaviour, 23(4), 331-362.

Rouleau, C., \& von Ranson, K. (2011). Potential risks of pro-eating disorder websites, Clinical Psychology Review, 31(4), 525-531.

Schneider, S., O'Donnell, L., Stueve, A., \& Coulter, R. (2012). Cyber-bullying, School Bullying, and Psychological Distress: A Regional Census of High School Students, American Journal of Public Health, 102(1), 171-178.

Shannon, D. (2008). Online sexual grooming in Sweden-Online and offline sex offences against children as described in Swedish police data. Journal of Scandinavian Studies in Criminology and Crime Prevention, 9, 160-180.

Sharpe, H., Musiat, P., Knapton, O., \& Schmidt, U. (2011). Pro-eating disorder websites: facts, fictions and fixes, Journal of Public Mental Health, 10(1), 34—44.

Sheehan, V., \& Sullivan, J. (2010). A qualitative analysis of child sex offenders involved in the manufacture of indecent images of children, Journal of Sexual Aggression, 16(2), $143-167$.

Smith, P., Mahdavi, J., Carvalho, M., Fisher, S., Russell, S., \& Tippett, N. (2008). Cyberbullying: its nature and impact in secondary school pupils, Journal of Child Psychology and Psychiatry, and Allied Disciplines, 49(4), 376-385.

Talbot, T. (2010). The Effects of Viewing Pro-Eating Disorder Websites: A Systematic Review, West Indian Medical Journal, 59(6), 686-697.

Von Weiler, J., Haardt-Becker, A., \& Schulte, S. (2010). Care and treatment of child victims of child pornographic exploitation (CPE) in Germany, Journal of Sexual Aggression, 16(2), $211-222$.

Williams, K., Guerra, N. (2007). Prevalence and predictors of internet bullying, The Journal of Adolescent Health, 41(6), S14-S21.

Wilson, J., Peebles, R., Hardy, K., \& Litt, I. (2006). Surfing for thinness: a pilot study of proeating disorder Web site usage in adolescents with eating disorders, Pediatrics, 118(6), e1635-43. 
Winder, B., \& Gough, B. (2010). 'I never touched anybody—that's my defence': A qualitative analysis of internet sex offender accounts, Journal of Sexual Aggression, 16(2), $125-141$.

Wolak, J., Mitchell, K., \& Finkelhor, D. (2007). Unwanted and wanted exposure to online pornography in a national sample of youth Internet users, Pediatrics, 119(2), 247257.

Ybarra, M., \& Mitchell, K. (2007). Prevalence and frequency of Internet harassment instigation: implications for adolescent health, The Journal of Adolescent Health, 41(2), 189-195.

Ybarra, M. (2004). Linkages between depressive symptomatology and Internet harassment among young regular Internet users, Cyberpsychology \& Behavior, 7(2), 247-258.

Ybarra, M., Mitchell, K., Wolak, J., \& Finkelhor, D. (2006). Examining characteristics and associated distress related to Internet harassment: findings from the Second Youth Internet Safety Survey, Pediatrics, 118(4), e1169—e1177. 
Table 1 Types of Harm Experienced by Minors as a Result of Online Risks

Types of harms $\%^{*} \quad \mathrm{~N}$

$$
\text { Health-related: }
$$

63

1. Pro-eating disorders

30

19

2. Self-harm

16

10

3. Suicides

14

9

4. Internet addiction

11

7

5. Other

29

14

Sex-related:

1. Processes

51

25

2. Risk factors and predictors

45

22

3. Effects

25

12

Cyber-bullying:

36

1. Prevalence

36

13

2. Impact of cyber-bullying on anxiety

17

6

3. Association between cyber-bullying and depression

11

4

4. Predictors of cyber-bullying

11

4

Note: Percentages are out of total number of articles in the given category. 